\title{
Characterization of telomeric regions from Ustilago maydis
}

\author{
Plinio A. Guzmán and J. Genaro Sánchez
}

Author for correspondence: Plinio Guzmán. Tel: +52 46251600 ext. 444, 447. Fax : +52 46251282.

Departamento de Ingeniería Genética de Plantas, Centro de Investigación y de Estudios Avanzados del IPN, Unidad Irapuato, Apartado Postal 629, 36500 Irapuato, Gto., Mexico

\begin{abstract}
The isolation of telomeres from the phytopathogenic fungus Ustilago maydis is described. The telomeric repeat from the plant Arabidopsis thaliana, ITTAGGG, cross-hybridizes to Ba/31-sensitive fragments of $U$. maydis DNA and detects many or all of the $U$. maydis chromosomes separated by pulsed-field gel electrophoresis (PFGE). This telomeric repeat was used to screen a library enriched for chromosome ends. Three clones were isolated which contained the tandemly repeated sequence TTAGGG. This sequence is identical to some known telomere repeats found in humans and other vertebrates as well as in some protozoa and moulds. In addition, the three telomeric clones had an almost identical 376 bp segment of middle-repeated telomere-associated sequences adjacent to the telomeric repeat. This segment hybridized to many or all $U$. maydis chromosomes separated by PFGE and showed a hybridization pattern in genomic digestions similar to that of the telomeric repeat. These results indicate that in $U$. maydis the same segment of telomere-associated sequences is located adjacent to the telomeric repeat in many or all chromosomes, which suggests that it may have a common role in chromosome function.
\end{abstract}

Keywords: Ustilago maydis, telomere, chromosome function

\section{INTRODUCTION}

In the last few years a dramatic increase of information has been generated in the molecular analysis of telomeres. These specialized DNA-protein complexes located at the chromosomal termini are required to stabilize the chromosomes and for the complete replication of DNA at the chromosome end. The telomere consists of tandemly repeated copies of a DNA sequence which contains clusters of $G$ residues oriented $5^{\prime}$ to $3^{\prime}$ towards the chromosome end. In telomeres of Arabidopsis, human, Tetrabymena and Chlamydomonas, among other eukaryotes, this sequence is perfectly repeated with little or no divergence. In others, like Saccharomyces cerevisiae and Dictyostelium, variations of a primary pattern are repeated. A repeated sequence is characteristic for each species and it is assumed to be present in all the chromosomes (Blackburn, 1991; Kipling \& Cooke, 1992; Zakian, 1989). An identical telomere repeat unit can be present in divergent species, ranging from protozoa to plants and humans. Also, telomeres from one species can stabilize

\footnotetext{
Abbreviations: ARS, autonomously replicating sequence; PFGE, pulsedfield gel electrophoresis; UTAS, Ustilago telomere-associated sequences. The GenBank accession numbers for the sequences reported in this paper are $X 77242$ and $X 77243$.
}

linear molecules in another one, even if their telomeric sequences are different (Zakian, 1989). The length of this repeated unit varies between species; in humans, differences in length have been observed depending on the cell type or on donor age (Harley et al., 1990; Hastie et al., 1990). In ciliated protozoa, synthesis of the G-rich strand is catalysed by an enzyme activity named telomere terminal transferase or telomerase. Telomerases are ribonucleoprotein enzymes, in which the RNA component contains sequences complementary to the telomeric repeat for which it is the template (Blackburn, 1992). Mutations in a gene that is thought to code for a component of the telomerase in S. cerevisiae, or mutations on the telomerase RNA gene of Tetrabymena, can lead to dramatic phenotypes: telomere shortening, chromosomal instability and cell death (Lumblad \& Szostak, 1989; Yu et al., 1990).

Studies in S. cerevisiae have determined that the only DNA sequence that is required for telomere function is the simple telomeric repeat. Although middle-repetitive DNA sequences are also often found adjacent to the telomere repeat, these sequences are not required for telomere function. For these sequences, called telomereassociated sequences, roles in recombination, replication and chromosome healing have been suggested; in $S$. cerevisiae these sequences are highly recombinogenic and 
contain putative DNA replication origins (Zakian, 1989). Telomere-associated sequences can extend from a few to hundreds of kilobases and have a polymorphic distribution. In S. cerevisiae two types of telomere-associated sequences, called $\mathrm{X}$ and $\mathrm{Y}^{\prime}$, are found. $\mathrm{Y}^{\prime}$ is a $6.7 \mathrm{~kb}$ highly conserved element present in 0 to 4 copies at the telomere region, and $\mathrm{X}$ is a 0.3 to $3.75 \mathrm{~kb}$ less conserved and less well characterized element (Chan \& Tye, 1983a, b). In humans, a few kilobases of telomereassociated sequences have been sequenced. These sequences are polymorphic in the genome and harbour a complex mixture of repetitive elements (Brown et al., 1990). In other organisms, such as Plasmodium falciparum, the telomere-associated repeats can extend for about $100 \mathrm{~kb}$ (Foote \& Kemp, 1989).

We are interested in the analysis of chromosome structure in Ustilago maydis, a basidiomycetous fungus that causes the smut disease in maize. This fungus has been used as a system to study genetic recombination (Holliday, 1974), DNA repair and replication (Holliday, 1974) and hostpathogen interactions (Banuett \& Herskowitz, 1989; Kronstad \& Leong, 1989; Schultz et al., 1990). U. maydis has several features that facilitate molecular genetic studies. It can be grown as a yeast-like uninucleate haploid in simple chemically defined media. Efficient transformation systems have been described and gene disruption by homologous recombination has been achieved (Fotheringham \& Holloman, 1989; Kronstad et al., 1989; Tsukuda et al., 1988; Wang et al., 1988). U. maydis has a haploid chromosome number of approximately 20 in the size range of 300 to more than $2000 \mathrm{~kb}$, which allows the use of pulsed-field gel electrophoresis (PFGE) for karyotyping (Kinscherf \& Leong, 1988). In this report we describe the molecular cloning of the telomeric repeat and of a segment of telomere-associated sequences from this fungus.

\section{METHODS}

Strains and DNA manipulation. The Eschericbia coli strain was XL-1 Blue (rec $A 1$ end $A 1$ gyr $A 96$ thi-1 bsdR 17 sup E44 relA1 lac $\left[\mathrm{F}^{\prime}\right.$ pro $A B$ lac $\left.\left.{ }^{\mathrm{q}} \mathrm{Z} \Delta \mathrm{M} 15 \mathrm{Tn} 10\left(\mathrm{Tet}^{\mathrm{r}}\right)\right]\right)$ from Stratagene. The Saccharomyces cerevisiae strain was YPH252 (MAT $\alpha$ ura3-52 bys2-

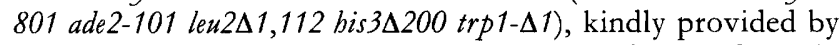
P. Hieter, Johns Hopkins University. The Ustilago maydis strain was UCM104 a $1 b 2$ leu1, kindly provided by William Holloman, Cornell University. Restriction enzymes and T4 DNA ligase were purchased from Gibco-BRL and ENZIBIOT; Bal31 was from Boehringer Mannheim. Plasmid isolation by the alkaline procedure and $E$. coli transformation by $\mathrm{CaCl}_{2}$ were performed as described by Sambrook et al. (1989). The DNA sequence was determined using the DNA Sequencing Kit, Sequenase version 2.0, from United States Biochemical. Single-stranded DNA for sequencing was prepared by the ssDNA template preparation procedure from Promega.

Isolation of U. maydis DNA. A modification of a procedure for yeast DNA isolation (Sherman et al., 1986) was used. Protoplasts were obtained from a cell pellet harvested from a 11 culture by incubating cells in SCS (1 M sorbitol, $20 \mathrm{mM}$ sodium citrate pH 5.8, $10 \mathrm{mM}$ EDTA) containing $20 \mathrm{mg}$ Novozym (Novobiolabs) $\mathrm{ml}^{-1}$ for $30 \mathrm{~min}$. Protoplasts were then washed in SCS and resuspended in $50 \mathrm{ml} 50 \mathrm{mM}$ Tris $/ \mathrm{HCl}(\mathrm{pH} \mathrm{7.4)}, 20 \mathrm{mM}$ EDTA. SDS ( $5 \mathrm{ml}$ of a $10 \%, \mathrm{w} / \mathrm{v}$, solution) was added, and the mixture incubated at $65^{\circ} \mathrm{C}$ for $30 \mathrm{~min}$. Potassium acetate $(15 \mathrm{ml}$ of a $5 \mathrm{M}$ solution) was added and the suspension was incubated for a further $60 \mathrm{~min}$ on ice. The cleared lysate was ethanolprecipitated, $\mathrm{RNase}$-treated, phenol $/ \mathrm{CHCl}_{3}$-extracted, ethanolprecipitated again, and the DNA was spooled out with a glass rod. The DNA was then resuspended in TE $(10 \mathrm{mM}$ Tris $/ \mathrm{HCl}$ $\mathrm{pH} 8,1 \mathrm{mM}$ EDTA). This procedure was also scaled down for $10 \mathrm{ml}$ cell cultures.

Ba/31 digestion of genomic DNA. U. maydis genomic DNA $\left(10 \mu \mathrm{g} \mathrm{ml}^{-1}\right)$ was digested for various periods of time with nuclease Bal31 $\left(0 \cdot 25 \mathrm{units}^{-1}\right)$ at $30^{\circ} \mathrm{C}$, in a solution containing $12 \mathrm{mM} \mathrm{CaCl}_{2}, 24 \mathrm{mM} \mathrm{MgCl}_{2}, 200 \mathrm{mM} \mathrm{NaCl}, 1 \mathrm{mM}$ EDTA and $20 \mathrm{mM}$ Tris/ $\mathrm{HCl}(\mathrm{pH} 8 \cdot 0)$. Reactions were stopped by adding EGTA to a final concentration of $20 \mathrm{mM}$. DNA was extracted with phenol $/ \mathrm{CHCl}_{3}$ and ethanol-precipitated. DNA was then digested with either Sau3AI or Bam HI and size-fractionated by agarose gel electrophoresis.

Construction and screening of a telomere-enriched library. The construction of the telomere-enriched library is depicted in Fig. 1. U. maydis DNA $(60 \mu \mathrm{g})$ was digested for $30 \mathrm{~s}$ with Bal31, and the ends were filled in with the Klenow fragment of DNA polymerase followed by digestion with Sau3AI. DNA fragments of $500-1000 \mathrm{bp}$ were size-selected on a $1 \%(\mathrm{w} / \mathrm{v})$ agarose gel and eluted from the gel using the Prep-A-gene DNA purification kit from Bio-Rad. Purified DNA was then ligated at high concentration to double-digested BamHI-HincII Bluescript-KS ${ }^{-}$vector (Stratagene), using a 10 -fold molar excess of vector to genomic DNA. The ligation mixture was then digested

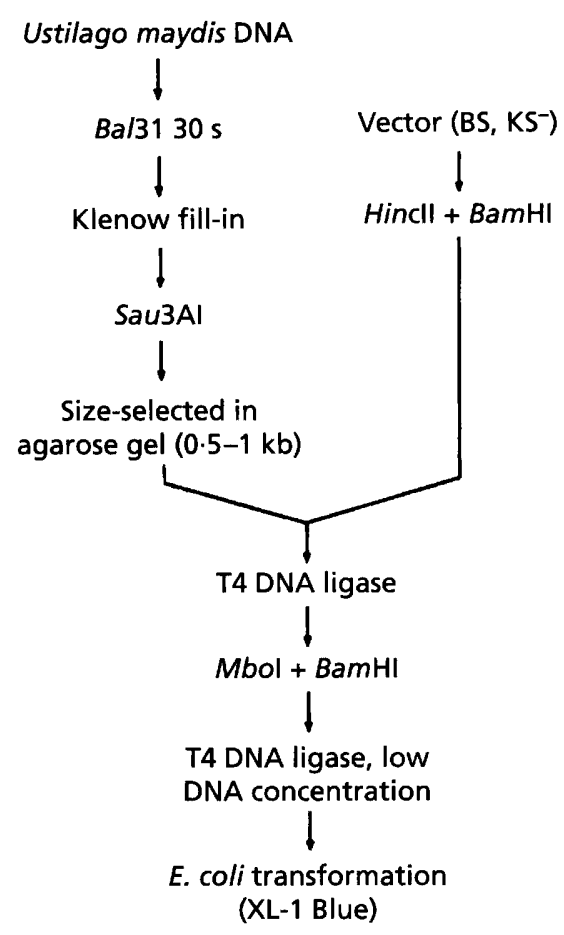

Fig. 1. Strategy for telomere cloning: construction of a $U$. maydis chromosome-end-enriched library. High molecular mass DNA was briefly treated with $B a / 31$ nuclease and then with Klenow enzyme to ensure the creation of blunt-ended sites for cloning. Sau3Al fragments of 500-1000 bp were size-selected in agarose gels and cloned into the Bluescript-KS- vector doubledigested with Hincll and BamHI. After ligation the mixture was transformed into $E$. coli strain XL-1 Blue (for details see Methods). 
with $\mathrm{MboI}$ and $\mathrm{BamHI}$, religated at a low DNA concentration and transformed into $E$. coli XL-1 Blue; MboI does not cut within vector sequences because the vector was prepared in an E. coli $\mathrm{dam}^{+}$host. Colonies were screened by hybridization on nylon membranes (Hybond-N, Amersham) and lysed according to the manufacturer's instructions. Membranes were prewashed in a solution containing $1 \% \mathrm{SDS}, 1 \mathrm{M} \mathrm{NaCl}, 50 \mathrm{mM}$ Tris $/ \mathrm{HCl}$ $\mathrm{pH} 7 \cdot 5$, and then prehybridized at $55^{\circ} \mathrm{C}$ in the same solution containing $25 \mu \mathrm{g}$ tRNA ml$l^{-1}$. Hybridization was done in a $1 \%$ SDS, $10 \%$ dextran sulfate, $25 \mu \mathrm{g}$ tRNA ml$l^{-1}$ solution at $55^{\circ} \mathrm{C}$. The probe, at a concentration of $5 \times 10^{5}$ c.p.m. $\mathrm{ml}^{-1}$, was the Pst1-BamHI insert from the Arabidopsis thaliana clone pAtT4 (Richards \& Ausubel, 1988); a Random Primer kit from Amersham was used for labelling. After hybridization, filters were washed in $2 \times \mathrm{SSPE} / 1 \% \mathrm{SDS}$ at room temperature, then in $0.5 \times \mathrm{SSPE} / 0.1 \% \mathrm{SDS}$ at $60^{\circ} \mathrm{C}(1 \times \mathrm{SSPE}$ is $0.15 \mathrm{M} \mathrm{NaCl}$, $0 \cdot 01 \mathrm{M}$ sodium phosphate, $1 \mathrm{mM}$ EDTA).

PFGE. To prepare DNA-agarose plugs from $U$. maydis, cells grown in $20 \mathrm{ml} \mathrm{MC}$ medium (Holliday, 1974) to $\mathrm{OD}_{600} 1 \cdot 2$ (approx. $10^{7}$ cells $\mathrm{ml}^{-1}$ ) were washed twice in $50 \mathrm{mM}$ EDTA and resuspended in $450 \mu \mathrm{l} \mathrm{SCE}(1 \mathrm{M}$ sorbitol, $20 \mathrm{mM}$ sodium citrate $\mathrm{pH} 5 \cdot 8,10 \mathrm{mM}$ EDTA). Novozyme $\left(0.5 \mu \mathrm{g} \mathrm{ml}^{-1}\right)$ was added, and $750 \mu \mathrm{l}$ of a $1 \%$ solution of low-melting-point agarose (BRL) prepared in $125 \mathrm{mM}$ EDTA ( $\mathrm{pH} 7 \cdot 5$ ). The mixture was allowed to solidify on ice for $10 \mathrm{~min}$. The solidified mixture was incubated first in LET buffer ( $500 \mathrm{mM}$ EDTA, $10 \mathrm{mM}$ Tris $/ \mathrm{HCl} \mathrm{pH} \mathrm{7.5,30} \mathrm{mM} \mathrm{2-mercaptoethanol)} \mathrm{at} \mathrm{room}$ temperature for $12 \mathrm{~h}$ and then in LDS buffer $(1 \%, \mathrm{w} / \mathrm{v}$, lithium dodecyl sulfate, $100 \mathrm{mM}$ EDTA, $10 \mathrm{mM}$ Tris $/ \mathrm{HCl} \mathrm{pH} \mathrm{8.0)} \mathrm{at}$ $50{ }^{\circ} \mathrm{C}$ for $24 \mathrm{~h}$ (Southern et al., 1987). DNA-agarose plugs were kept at $4{ }^{\circ} \mathrm{C}$ in $50 \mathrm{mM}$ EDTA. PFGE was performed on a Rotaphor unit (Biometra Rotaphor type IV). Electrophoresis was carried out in $1 \%$ agarose gels $(20 \times 20 \mathrm{~cm})$ at $13^{\circ} \mathrm{C}$ in $0.5 \times \mathrm{TBE}$ buffer $(1 \times \mathrm{TBE}$ is $0.1 \mathrm{M}$ Tris, $0.1 \mathrm{M}$ boric acid, $2 \mathrm{mM}$ EDTA). Conditions used for separation of $U$. maydis chromosomes were $200 \mathrm{~V}$ for $26 \mathrm{~h}$; the pulse time decreased linearly from 120 to $30 \mathrm{~s}$ and the angle between the orientation of the homogeneous electronic field decreased linearly from $110^{\circ}$ to $99^{\circ}$.

Southern hybridization. Southern blotting was done on nylon membranes (Hybond $\mathrm{N}^{+}$, Amersham) (Church \& Gilbert, 1984). Hybridizations were carried out in $0.5 \mathrm{M} \mathrm{Na}_{2} \mathrm{HPO}_{4}$ (pH 7.2), $7 \%$ SDS, $1 \mathrm{mM}$ EDTA, $1 \%(\mathrm{w} / \mathrm{v})$ BSA at a probe concentration of $10^{6} \mathrm{c}$.p.m. ml $\mathrm{m}^{-1}$. Low-stringency hybridization was done at $55^{\circ} \mathrm{C}$ followed by washes with $2 \times$ SSPE, $1 \%$ SDS at $55^{\circ} \mathrm{C}$. High-stringency hybridization was at $65^{\circ} \mathrm{C}$ followed by washes with $0 \cdot 2 \times \mathrm{SSPE}, 0 \cdot 1 \% \mathrm{SDS}$ at $65^{\circ} \mathrm{C}$. For removal of probes a solution of $0.1 \%$ SDS and $0 \cdot 1 \times$ SSPE was boiled, poured on the membrane and allowed to cool at room temperature; this treatment was repeated at least twice.

\section{RESULTS AND DISCUSSION}

\section{Identification of $U$. maydis telomeric DNA}

The conservation of telomere sequences among divergent eukaryotes has facilitated the characterization of telomeric DNA from new species. Telomeric DNA from several organisms has been identified and cloned by using telomeric repeats from non-related organisms as probes. The telomeric repeat from the plant Arabidopsis thaliana [(TTTAGGG $)_{n}$, clone pAtT4] (Richards \& Ausubel, 1988) has been used to identify telomere DNA from plants (Ganal et al., 1991) and to clone telomere sequences from species such as Chlamydomonas reinbardtii (Petracek et al., 1990). To test whether the $A$. thaliana telomeric repeat cross-hybridized with $U$. maydis DNA, we digested high molecular mass $U$. maydis DNA for progressively increasing lengths of time with $B a / 31$ followed by digestion with SaußAI or BamHI. Analysis of the digests by electrophoresis on agarose gels, transfer to nylon membranes, and hybridization to the insert of the $A$. thaliana pAtT4 clone showed a shift of the hybridization signal towards the lower molecular mass (Fig. 2a). This result suggests that the $A$. thaliana telomere repeat crosshybridizes with the ends of $U$. maydis chromosomal DNA molecules. This type of shift was not observed when the same filter was probed with a non-repeated probe (Fig. 2c).

\section{Cloning and sequence analysis of the $U$. maydis telomeric repeat}

Telomeric DNA is not usually represented in genomic libraries. End-enriched libraries have to be constructed to clone the ends of the chromosomes (Richards \& Ausubel, 1988; Van der Ploeg et al., 1984). As shown in Fig. 2(a), pAtT4 hybridized to a smear on U. maydis DNA digested with Sau3AI, suggesting that a SauBAI site is present close to the end of several of the $U$. maydis chromosomes. We size-selected $0.5-1.0 \mathrm{~kb}$ fragments of $U$. maydis DNA digested with this enzyme to construct a telomereenriched library (see Fig. 1). Screening of 8000 clones by hybridization to the pAt 44 probe revealed three positive clones. These clones contained a $600 \mathrm{bp}$ DNA insert which strongly hybridized to the $A$. thaliana telomeric repeat. DNA sequence analysis of the three clones, pUT1, pUT2 and pUT3, revealed a 6 bp repeat extending from the blunt-end cloning site (Fig. 3b). The sequence CCCTAA was perfectly repeated in the three clones; pUT1 and pUT2 each had 37 tandemly repeated copies and pUT3 had 39 tandemly repeated copies. The complementary sequence TTAGGG correlates with their location towards the $3^{\prime}$ end of the chromosome, as has been also found in other organisms. As expected for telomeric DNA, the sequence contained in these clones is sensitive to exonuclease Bal31 digestion (Fig. 2a); it is remarkably similar to the $A$. thaliana telomere repeat which was used as a probe, and the G-rich strand is oriented towards the $3^{\prime}$ end of the chromosome. The DNA sequence of this telomeric repeat is identical to the sequence found in humans and other vertebrates (Meyne et al., 1989; Moyzis et al., 1988), in Physarum (Forney et al., 1987), Trypanosoma (Blackburn \& Challoner, 1984; Van der Ploeg et al., 1984) and Neurospora (Schechtman, 1990), where the telomere sequences consist of tandem repeats of the fixed unit TTAGGG.

\section{Sequence analysis of the telomere-associated sequences}

In addition to the telomeric repeat, the adjacent regions also had stretches of repeated sequences. These sequences are referred to as telomere-associated sequences. No function has yet been identified for telomere-associated sequences, although roles in replication, healing of broken chromosomes after radiation damage or protection of 
(a)

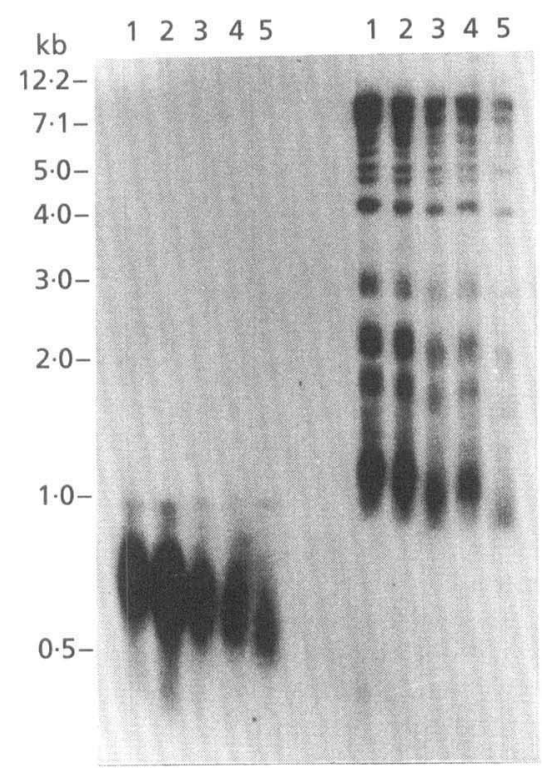

(b)
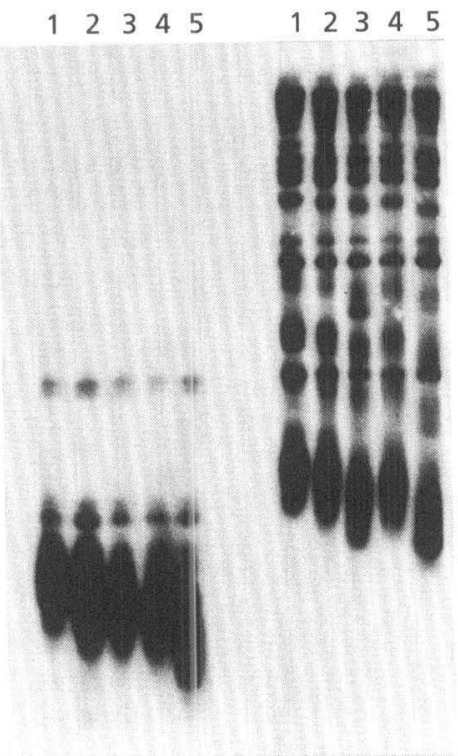

(c)

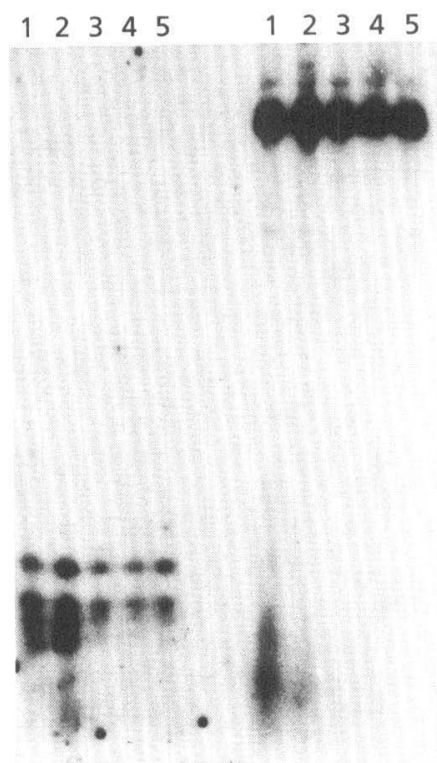

\begin{abstract}
Fig. 2. Ba/BI sensitivity of SaUBAI and BamHI fragments identified by the $A$. thaliana telomeric repeat and the $U$. maydis UTAS probes. U. maydis DNA was digested for 0 (lane 1), 5 (lane 2), 10 (lane 3), 15 (lane 4) and 20 (lane 5) min with Ba/31 nuclease and then digested with Sau3Al (left lanes) or BarnHI (right lanes). DNA was size-fractionated by agarose gel electrophoresis and transferred to a nylon membrane. The blot was first probed with the $A$. thaliana telomeric sequence from clone pAtT4 (a), rehybridized to the $U$. maydis UTAS region, a Sau3AI-Hincll insert from clone UT1 (see Fig. 3 ) (b) and then rehybridized again to the $U$. maydis Hsp70 sequences obtained from plasmid pCM54 (Tsukuda et al., 1988) (c). The blot shown in (a) was hybridized and washed at low stringency, those in (b) and (c) at high stringency. The probe was removed after each hybridization. The positions of molecular size markers (1 kb ladder from Gibco-BRL) are shown on the left.
\end{abstract}

chromosomes from degradation have been proposed (Zakian, 1989). The fact that the smallest yeast chromosome lacked detectable amounts of the telomereassociated sequences $\mathrm{X}$ and $\mathrm{Y}^{\prime}$ and that large chromosomes seem to contain these elements suggests that they are required for stable maintenance of large natural chromosomes (Zakian \& Blanton, 1988). DNA sequence analysis of the region adjacent to the telomere in clones pUT1, pUT2 and pUT3 revealed an almost identical sequence in the three clones: pUT1 and pUT2 were identical and pUT3 had $90 \%$ identity (Fig. 3a). Although the three $U$. maydis clones were isolated as independent clones, two have an identical DNA sequence; at this point we can not tell whether these two correspond to the same telomere or if they come from different chromosome ends. The $376 \mathrm{bp}$ of this sequence show some noteworthy features (Fig. 3a, b) : a 198 bp G-rich region (42\%) and a $87 \mathrm{bp} G$-rich region flank a $91 \mathrm{bp} \mathrm{A}+\mathrm{T}$ rich region $(88 \%)$. We will refer to this sequence as UTAS, for Ustilago telomere-associated sequences. In other species, one characteristic of telomere-associated sequences is their polymorphic distribution (Zakian, 1989). In S. cerevisiae and in humans these sequences are organized as a series of middle-repeated sequences, which are found in some but not all the chromosomes, with their distribution varying among different chromosomes (Brown et al., 1990; Zakian \& Blanton, 1988). With the analysis of our clones we can not yet determine the extent of the telomere-associated elements in $U$. maydis. The cloning and DNA sequence analysis of larger segments of DNA from the telomere region towards the centromere will define more precisely the structure of the telomere-associated elements in $U$. maydis.

Interestingly, adjacent to the telomere repeat in the $U$. maydis UTAS there is an A + T-rich region of some $90 \mathrm{bp}$. Autonomously replicating sequences (ARSs) have been also found associated with the yeast $\mathrm{X}$ and $\mathrm{Y}^{\prime}$ elements (Chan \& Tye, 1980). Yeast ARSs are some $100 \mathrm{bp}$ in length and have a high $\mathrm{A}+\mathrm{T}$ content; all ARSs contain one or more copies of an 11 nucleotide consensus sequence (Newlon, 1988). Thus, it could be speculated that the $U$. maydis UTAS could have an ARS function. ARSs have already been isolated from $U$. maydis (Tsukuda et al., 1988). These sequences, called UARS1, were identified by searching for plasmids containing random genomic fragments which increased the frequency of transformation. No obvious sequence homology could be detected between UARS1 and UTAS (data not shown). Thus, if UTAS have a function in chromosome replication it may be as a special type of replication origin for chromosome termini, although other types of function can be hypothesized.

\section{Chromosomal distribution of the telomeric repeat and of telomere-associated sequences}

It is assumed that telomeric repeated sequences are found in all of the chromosome ends of an organism, whereas 
(a)

\begin{tabular}{|c|c|c|}
\hline 1 & $\begin{array}{l}\text { UT1 } \\
\text { UT3 }\end{array}$ & 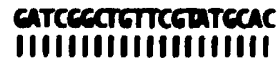 \\
\hline 81 & $\begin{array}{l}\text { Ur1 } \\
\text { Ur3 }\end{array}$ & $\begin{array}{l}\text { cececheataTatangTeA } \\
\text { IIIIIIIIIIIIIIIIII }\end{array}$ \\
\hline 161 & $\begin{array}{l}\text { UT1 } \\
\text { UT3 }\end{array}$ & 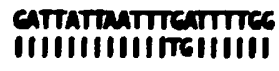 \\
\hline 241 & $\begin{array}{l}\mathbf{U T 1} \\
\mathbf{U} \mathbf{3}\end{array}$ & 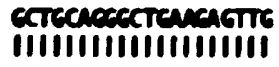 \\
\hline & $\begin{array}{l}\text { or } \\
\text { or: }\end{array}$ & $\begin{array}{l}\text { темтоттенасесестеS } \\
\text { IIIIIIIIIIIIIIIII }\end{array}$ \\
\hline
\end{tabular}

(b)

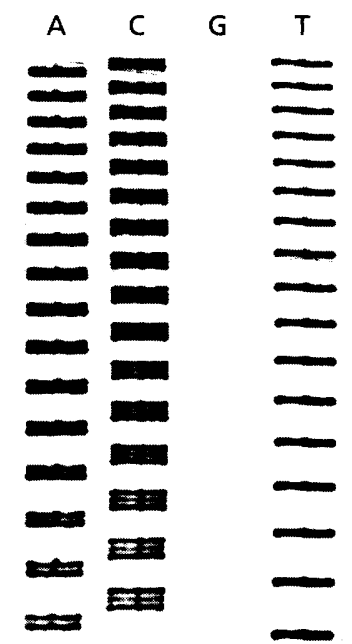

TecCTtCacegteeATeCT IIIIIIIIIIIIIIIIII

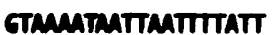
IIIIGIIIIIIIIIIIII!

TEecencosenovteAcCag ilililiatrecelilike

tatcacecesetcatagta GIIIIIIIIIII ITGITIG

Accecteacececteeacece IIIIAIIIGIIIIIIIII
CACECGTECATGTATGTTG IIIIIIIIIIIIIIAIIII

TGTATTMATITIITITA IIIIIIIIIIIIIIIIIIel

TEnCCGATCTEATATEG IIIIIIIIIIIIIIIIIIIa

\section{TITCTMTGTreancace}

|AIGIIGGIIIGIGIITII

TECACGETTCACOCCTGAT |00000000|IIIIIIIIIIII
AGGTGGTATGCETCANT

IIIIIIIIIIIIIIIIIIII

ATGTTGGATTMMTTTGGA

IIIIIIIIIIIIIIII

TEGGTTITTTETECCG

IIIIIIIIIIIIIIIIII

gGATGATGGeATCAGAGAT

IIIIIGIIIIIIIIGII

AGGGCTAGCG)37-35

|+|| |IIIII

(c)

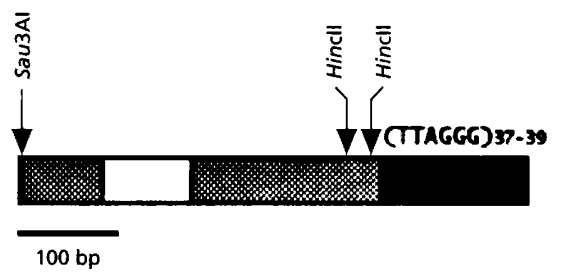

Fig. 3. DNA sequence of the $U$. maydis telomeric region. (a) Sequences of the telomere-associated sequences in clones pUT1 and pUT3 (clones pUT1 and pUT2 have an identical sequence). The sequence is written in the usual $5^{\prime}$ to $3^{\prime}$ direction towards the chromosome end. The Sau3Al site of the insert was used for cloning into the BamHI site of the vector; the G nucleotide of the site corresponds to the first nucleotide of the sequence. The fusion of the blunt-end cloning site of the vector to the telomeric sequences is not shown. |, Nucleotide identical to the nucleotide above; *, missing nucleotide. (b) Primary DNA sequence of the telomere repeat in clone pUT1, determined by the dideoxy procedure. (c) Schematic illustration of the telomeric region. The stippled area corresponds to G-rich regions: nucleotides $1-87, G=46 \%$, and nucleotides $179-384$ (198 bp) $G=42 \%$. An $A+T$-rich region, nucleotides $88-178$, is shown in white, $T=52 \%$ and $A=31 \%$, and an area corresponding to the telomeric repeat is shown in black.

the telomere-associated sequences are often found at some but not all the chromosome ends (Zakian, 1989). To confirm that the $A$. thaliana telomere cross-hybridizes with all of the $U$. maydis chromosomes and to examine the distribution of the UTAS we initially used PFGE. As probes we used the $A$. thaliana telomeric repeat and a 330 bp restriction fragment which contains the UTAS region and no telomeric repeat. Although clusters of bands in the range 600 to $\geqslant 1100 \mathrm{~kb}$ were not resolved when $U$. maydis chromosomes were separated by PFGE, the result showed that the telomeric repeat and the UTAS hybridized to all of the $U$. maydis chromosomes that could be distinguished after ethidium bromide staining (Fig. 4a, lanes 2 and 3). The fact that the intensity of hybridization with telomeric or UTAS probes was comparable, both between the probes and to the ethidium bromide staining, supports this result.

To determine whether UTAS were found at the chromo- somal end adjacent to the telomeric repeat, $U$. maydis DNA was digested separately with three restriction enzymes, electrophoresed on an agarose gel, and hybridized first to the telomere repeat and then rehybridized to the UTAS probe. At least 25 fragments hybridized for each digestion. In each of the three digestions the pattern of hybridization was very similar with either probe. The fact that the same size fragments hybridize with the two probes suggests that they are contained within the same fragment. These results suggest that the UTAS region is found in all of the $U$. maydis chromosomes at a position adjacent to the telomere repeat. Some differences can be seen, though: EcoRI fragments of about 7.0 and $3.0 \mathrm{~kb}$, Bam HI fragments of about $6 \cdot 0,4.5$ and $3.0 \mathrm{~kb}$, and HindIII fragments of about 13.0 and $6.8 \mathrm{~kb}$ (Fig. $4 \mathrm{~b}$ ).

In various species telomere-like sequences can be found at non-telomeric positions in the chromosome. They can be found close to the telomere region as in $S$. cerevisiae, where 

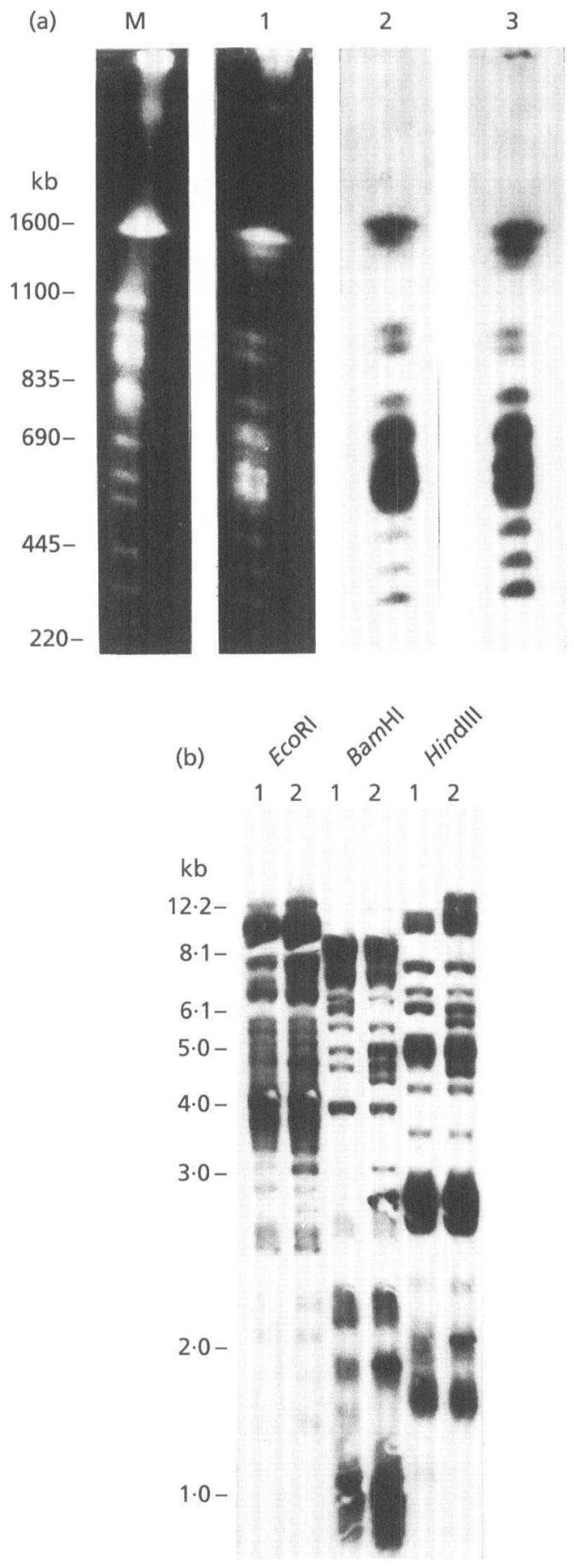

Fig. 4. Distribution of telomeric and telomere-associated sequences on the $U$. maydis chromosomes. (a) DNA-agarose plugs were prepared from $S$. cerevisiae (lane $M$, used as a molecular size marker) and from $U$. maydis strain UCM104. Chromosomes were subjected to PFGE as described in Methods. Several lanes of UCM104 were separated and transferred to a nylon membrane: lane 1, ethidium bromide staining; lane 2 , probed with the $A$. thaliana telomere repeat; lane 3 , probed with the $U$. maydis UTAS region. (b) $U$. maydis DNA was prepared from strain UCM104, digested to completion with EcoRI (first two lanes), BamHI (third and fourth lanes) and Hindlll (last two lanes). DNAs were size-fractionated by agarose gel electrophoresis and transferred to a nylon membrane. The blot was probed with the $A$. thaliana telomere repeat (lanes short tracts of telomeric sequences are at the junctions of telomere-associated elements (Walmsley et al., 1984). In vertebrates and plants telomere-like sequences have also been found at the centromere regions (Allshire et al., 1988; Richards et al., 1991). Telomere-like sequences are insensitive to Bal31 nuclease; their electrophoretic mobility is not affected in a Bal31 kinetic analysis when probed with a telomeric repeat (Richards et al., 1991). In the Sau3AI digestion of $U$. maydis DNA hybridized with pAt'T4 there was a fragment of approximately $1.0 \mathrm{~kb}$ which was $B a / 31$ insensitive. A similar analysis performed with the UTAS region (Fig. 2b), indicated that there are at least four bands $(0.8 \mathrm{~kb}, 0.9 \mathrm{~kb}$ and two of $1.7 \mathrm{~kb})$ which are $B a l 31$ insensitive. These results suggest that telomere-like and UTAS-like sequences are also located in non-telomeric regions in the $U$. maydis genome. Thus, it would be interesting to investigate further the chromosomal location of telomere-like and UTAS-like sequences in U. maydis.

\section{ACKNOWLEDGEMENTS}

We wish to thank Eric Richards and William Holloman for plasmids and strains, Beatriz Jiménez for DNA sequence analysis and Gabriela Olmedo for critical review of the manuscript. This work was supported in part by research grants $0024 \mathrm{~N}$ and $0072 \mathrm{~N}$ from Consejo Nacional de Ciencia y Tecnología and 334.9 from Consejo del Sistema Nacional de Educación Tecnológica, México, to P.G.

\section{REFERENCES}

Allshire, R. C., Gosden, J. R., Cross, S. H., Cranton, G., Raut, D., Suguwara, N., Szostak, J. W., Fantes, P. A. \& Hastie, N. D. (1988). Telomeric repeat from $T$. thermophila cross hybridizes with human telomeres. Nature 332, 650-659.

Banuett, F. \& Herskowitz, I. (1989). Different $a$ alleles of Ustilago maydis are necessary for maintenance of filamentous growth but not for meiosis. Proc Natl Acad Sci US A 86, 5878-5882.

Blackburn, E. H. (1991). Structure and function of telomeres. Nature 350, 569-573.

Blackburn, E. H. (1992). Telomerases. Annu Rev Biochem 61, 113-129.

Blackburn, E. H. \& Challoner, P. B. (1984). Identification of a telomeric DNA sequence in Trypanosoma brucei. Cell 36, 447-457.

Brown, W. R. A., MacKinnon, P. J., Villasante, A., Spurr, N., Buckle, V. J. \& Dobson, M. J. (1990). Structure and polymorphism of human telomere-associated DNA. Cell 63, 119-132.

Chan, C. S. M. \& Tye, B.-K. (1980). Autonomously replicating sequences in Saccharomyces cerevisiae. Proc Natl Acad Sci USA 77, 6329-6333.

Chan, C. S. M. \& Tye, B.-K. (1983a). A family of Saccharomyces cerevisiae repetitive autonomously replicating sequences that have very similar genomic environments. J Mol Biol 168, 505-523.

Chan, C. S. M. \& Tye, B.-K. (1983b). Organization of DNA sequences and replication origins at yeast telomeres. Cell 33, 563-573.

labelled 1), the probe was then removed and the membrane was rehybridized with the $U$. maydis UTAS probe (lanes labelled 2). Probes are the same as for Fig. 2. 
Church, G. M. \& Gilbert, W. G. (1984). Genomic sequencing. Proc Natl Acad Sci US A 81, 1991-1995.

Foote, S. J. \& Kemp, D. J. (1989). Chromosomes of malaria parasites. Trends Genet 5, 337-342.

Forney, J., Henderson, E. R. \& Blackburn, E. H. (1987). Identification of the telomeric sequence of the acellular slime molds Didynium iridis and Pbysarum polycephalum. Nucleic Acids Res 15, 9143-9152.

Fotheringham, S. \& Holloman, W. K. (1989). Cloning and disruption of Ustilago maydis genes. Mol Cell Biol 9, 4052-4055.

Ganal, M. W., Lapitan, N. L. V. \& Tanksley, S. D. (1991). Macrostructure of the tomato telomeres. Plant Cell 3, 87-94.

Harley, C. B., Futchter, A. B. \& Greider, C. W. (1990). Telomeres shorten during ageing of human fibroblasts. Nature 345, 458-460.

Hastie, N. D., Dempster, M., Dunlop, M. G., Thompson, A. M., Green, D. K. \& Allshire, R. C. (1990). Telomere reduction in human colorectal carcinoma and with ageing. Nature 346, 866-871.

Holliday, R. (1974). Ustilago maydis. In Handbook of Genetics, pp. 575-595. Edited by R. C. King. New York: Plenum Press.

Kinscherf, T. G. \& Leong, S. A. (1988). Molecular analysis of the karyotype of Ustilago maydis. Chromosoma 96, 427-433.

Kipling, D. \& Cooke, H. J. (1992). Beginning or end? Telomere structure, genetics and biology. Hum Mol Genet 1, 3-6.

Kronstad, J. W. \& Leong, S. A. (1989). Isolation of two alleles of the $b$ locus of Ustilago maydis. Proc Natl Acad Sci US A 86, 978-982.

Kronstad, J. W., Wang, J., Covert, S. F., Holden, D. W., McKnight, G. L. \& Leong, S. A. (1989). Isolation of metabolic genes and demonstration of gene disruption in the phytopathogenic fungus Ustilago maydis. Gene 79, 97-100.

Lumblad, V. \& Szostak, J. W. (1989). A mutant with a defect in telomere elongation leads to senescence in yeast. Cell 57, 633-643.

Meyne, J., Ratliff, R. L. \& Moyzis, R. K. (1989). Conservation of the

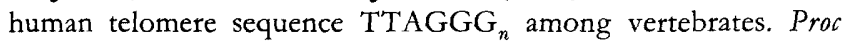
Natl Acad Sci USA 86, 7049-7053.

Moyzis, R. K., Buckingham, J. M., Cram, L. S., Dani, M., Deaven, L. L., Jones, M. D., Meyne, J., Ratliff, R. L. \& Wu, J.-R. (1988). A highly conserved repetitive DNA sequence, (TTAGGG) ${ }_{n}$, present at the telomeres of human chromosomes. Proc Natl Acad Sci USA 85, 6622-6626.

Newlon, C. S. (1988). Yeast chromosome replication and segregation. Microbiol Rev 52, 568-601.

Petracek, M. E., Lefebvre, P. A., Silflow, C. D. \& Berman, J. (1990). Chlamydomonas telomere sequences are $\mathrm{A}+\mathrm{T}$-rich but contain three consecutive GC base pairs. Proc Natl Acad Sci USA 87, $8222-8226$.

Richards, E. J. \& Ausubel, F. M. (1988). Isolation of a higher eukaryotic telomere from Arabidopsis thaliana. Cell 53, 127-136.

Richards, E. J., Goodman, H. M. \& Ausubel, F. M. (1991). The centromere region of Arabidopsis thaliana chromosome 1 contains telomere-similar sequences. Nucleic Acids Res 19, 3351-3357.

Sambrook, J. E., Fritsch, E. F. \& Maniatis, T. (1989). Molecular Cloning, a Laboratory Manual, 2nd edn. Cold Spring Harbor, NY: Cold Spring Harbor Laboratory.

Schechtman, M. G. (1990). Characterization of telomere DNA from Neurospora crassa. Gene 88, 159-165.

Schulz, B., Banuett, F., Dahl, M., Schleslinger, R., Schäfer, W., Martin, T., Herskowitz, I. \& Kahmann, R. (1990). The $b$ alleles of $U$. maydis, whose combinations program pathogenic development, code for polypeptides containing a homeodomain-telated motif. Cell 60, 295--306.

Sherman, F., Fink, G. R. \& Hicks, J. B. (1986). Methods in Yeast Genetics. Cold Spring Harbor, NY: Cold Spring Harbor Laboratory. Southern, E. M., Brown, W. R. A. \& Fletcher, D. S. (1987). A model for the separation of large DNA molecules by crossed field gel electrophoresis. Nucleic Acids Res 15, 5925-5943.

Tsukuda, T., Carleton, S., Fotheringham, S. \& Holloman, W. K. (1988). Isolation and characterization of an autonomously replicating sequence from Ustilago maydis. Mol Cell Biol 8, 3703-3709.

Van der Ploeg, L. H. T., Liu, A. Y. C. \& Borst, P. (1984). Structure of the growing telomeres of trypanosomes. Cell 36, 459-468.

Walmsley, R. W., Chan, C. S. M., Tye, B.-K. \& Petes, T. D. (1984). Unusual DNA sequences associated with the ends of yeast chromosomes. Nature 310, 157-160.

Wang, J., Holden, D. W. \& Leong, S. A. (1988). Gene transfer system for the phytopathogenic fungus Ustilago maydis. Proc Natl Acad Sci US A 85, 865-869.

Yu, G.-L., Bradley, J. D., Attardi, L. D. \& Blackburn, E. H. (1990). In vivo alteration of telomere sequences and senescence caused by mutated Tetrabymena telomerase RNAs. Nature 344, 126-132.

Zakian, V. A. (1989). Structure and function of telomeres. Annu Rev Genet 23, 579-604.

Zakian, V. A. \& Blanton, H. M. (1988). Distribution of telomereassociated sequences on natural chromosomes in Saccharomyces cerevisiae. Mol Cell Biol 8, 2257-2260.

Received 16 July 1993; accepted 2 December 1993. 